\title{
Structure and dynamics of cationic membrane peptides and proteins: Insights from solid-state NMR
}

\author{
Mei Hong* and Yongchao Su \\ Department of Chemistry, lowa State University, Ames, lowa \\ Received 30 December 2010; Revised 14 January 2011; Accepted 18 January 2011 \\ DOI: $10.1002 /$ pro.600 \\ Published online 22 February 2011 proteinscience.org
}

\begin{abstract}
Many membrane peptides and protein domains contain functionally important cationic Arg and Lys residues, whose insertion into the hydrophobic interior of the lipid bilayer encounters significant energy barriers. To understand how these cationic molecules overcome the free energy barrier to insert into the lipid membrane, we have used solid-state NMR spectroscopy to determine the membrane-bound topology of these peptides. A versatile array of solid-state NMR experiments now readily yields the conformation, dynamics, orientation, depth of insertion, and site-specific protein-lipid interactions of these molecules. We summarize key findings of several Arg-rich membrane peptides, including $\beta$-sheet antimicrobial peptides, unstructured cell-penetrating peptides, and the voltage-sensing helix of voltage-gated potassium channels. Our results indicate the central role of guanidinium-phosphate and guanidinium-water interactions in dictating the structural topology of these cationic molecules in the lipid membrane, which in turn account for the mechanisms of this functionally diverse class of membrane peptides.
\end{abstract}

Keywords: membrane protein; solid-state NMR; antimicrobial peptides; cell penetrating peptides; structure; dynamics; topology

\section{Introduction}

In this review, we will explore the structure and dynamics of cationic membrane peptides and proteins in lipid bilayers as learned from solid-state NMR. Although hydrophobic amino acid residues dominate in large functional membrane proteins, cationic residues such as Arg and Lys are numerous in many membrane peptides, whose biological functions require them to disrupt or cross the lipid membrane (Table I). These peptides include the large family of immune-defense molecules called antimicrobial pep-

${ }^{*}$ Correspondence to: Mei Hong, Department of Chemistry, lowa State University, Ames, IA 50011. E-mail: mhong@iastate.edu.

Grant sponsor: NIH; Grant number: GM-066976. tides $(\mathrm{AMPs})^{1}$ and the family of delivery molecules called cell-penetrating peptides (CPPs), ${ }^{2}$ which contain $\sim 30$ to $100 \%$ cationic Arg and Lys residues. In larger membrane proteins rich in hydrophobic residues, sparsely distributed cationic residues have also been found to play key roles in function. For example, the voltage-sensing S4 helix of voltagegated potassium channels contains Arg and Lys residues at every third position, which act as the gating charges that respond to membrane potential changes to open and close the channels. ${ }^{3}$

The fascinating fundamental question about these functionally diverse membrane peptides and protein domains is how the cationic residues are imported into and accommodated by the low-dielectric hydrophobic interior of the lipid bilayer against 
Table I. Examples of Arg-Rich Membrane Peptides and Protein Domains

\begin{tabular}{llc}
\hline \multicolumn{1}{c}{ Peptide } & \multicolumn{1}{c}{ Sequence } & No. Arg, No. Lys/No. residues \\
\hline AMP: Protegrin 1 & RGGRLCYCRRRFCVCVGR & $6 \mathrm{Arg} / 18$ \\
AMP: Tachyplesin I & KWCFRVCYRGICYRRCR & $5 \mathrm{Arg}, 1 \mathrm{Lys} / 18$ \\
CPP: HIV TAT(48-60) & GRKKRRQRRRPPQ & $6 \mathrm{Arg}, 2 \mathrm{Lys} / 13$ \\
CPP: penetratin & RQIKIWFQNRRMKWKK & $3 \mathrm{Arg}, 4 \mathrm{Lys} / 16$ \\
CPP: Arg8 & RRRRRRRR & $12 \mathrm{Arg} / 12$ \\
KvAP S4 helix & LGLFRLVRLLRGLRILLII & $4 \mathrm{Arg} / 19$ \\
\hline
\end{tabular}

the free energy barrier. The free energy $(\Delta G)$ of insertion of the 20 amino acids from aqueous solution to lipid membranes has been measured using an endoplasmic reticulum translocon system. ${ }^{4}$ Although high-resolution details are not provided by this technique, the resulting equilibrium constants of partition are qualitatively consistent with the expectation that hydrophobic residues have favorable (negative) $\Delta G$ of transfer into the lipid bilayer, whereas polar and charged residues encounter significant barriers. The $\Delta G$ for Arg and Lys was estimated to be +2.5 to $+2.7 \mathrm{kcal} / \mathrm{mol}^{4}$ for transfer to the center of the lipid bilayer where the dielectric constant is the lowest. Thus, for predominantly cationic AMPs and CPPs, where the cationicity is not balanced by many hydrophobic residues, it is puzzling how they overcome the free energy barrier to insert into the center of the membrane, if they indeed do, and moreover how the solvent, the lipid bilayer, adapts to these charges. A second question is how protein insertion into lipid bilayers depends on the secondary structure. Although $\alpha$-helices are stabilized by intramolecular H-bonds, $\beta$-strands are stabilized by intermolecular ones. Thus, the membrane insertion of $\beta$-sheet-rich peptides, such as some AMPs, would suggest oligomerization. ${ }^{5}$ Even more unusual is that some highly charged CPPs such as the HIV TAT peptide are unstructured and thus do not possess any peptide-peptide H-bonds, ${ }^{6}$ yet they are extremely facile in crossing the lipid bilayer. Thus, elucidating the molecular structure and dynamics of these cationic membrane peptides and their interaction with the environment is crucial for understanding their mechanisms of action.

Many molecular dynamics (MD) simulations have been carried out to understand the mode of insertion of Arg-rich peptides. ${ }^{7-10}$ But solid-state NMR is by far the most direct experimental technique to extract atomic-level structural information about the peptide-membrane interactions of these systems. In this article, we will review the solidstate NMR techniques that are now available to determine the structure and dynamics of membranebound proteins, ${ }^{11-13}$ then summarize key findings of several representative AMPs, CPPs, and the voltagesensing S4 helix of a potassium channel. Finally, we will summarize the common principles of membrane interactions of these Arg-rich peptides.

\section{Solid-State NMR Techniques for Studying Protein-Membrane Interactions}

Solid-state NMR is a highly versatile and rich spectroscopic technique that can yield atomic-level information about the conformation, dynamics, orientation, depth of insertion of membrane proteins, and lipid-protein interactions. Protein conformation, expressed in terms of $(\phi, \psi, \chi)$ torsion angles, can now be determined semiquantitatively from ${ }^{13} \mathrm{C}$ and ${ }^{15} \mathrm{~N}$ chemical shifts and ever improving computational methods promise more accurate prediction of these protein secondary structure from chemical shifts alone. ${ }^{14}$ These chemical shifts can now be measured with multidimensional ${ }^{13} \mathrm{C}-{ }^{13} \mathrm{C}$ and ${ }^{13} \mathrm{C}-{ }^{15} \mathrm{~N}$ correlation experiments under magic-angle spinning (MAS) [Fig. 1(a)]. ${ }^{15,16}$ Torsion angles can also be directly quantified by correlating dipolar interactions of the relevant bonds ${ }^{17,18}$ or by measuring internuclear distances. ${ }^{19}$ Once the secondary structure is known, the 3D fold of the protein can be obtained by measuring inter-residue ${ }^{13} \mathrm{C}-{ }^{13} \mathrm{C}$ distances using $2 \mathrm{D}$ or $3 \mathrm{D}$ correlation experiments with long mixing times. ${ }^{20,21}$ This full-structure determination approach has been applied to a human $\alpha$-defensin, HNP-1. ${ }^{22,23}$

The monomer 3D structure forms the basis for determining the oligomeric structure of membrane proteins. To constrain oligomeric packing, one needs to have intermolecular distances well beyond the typical range of $5 \AA$ for NMR. We developed a ${ }^{19} \mathrm{~F}$ spin diffusion NMR approach based on the CODEX pulse sequence to measure intermolecular distances up to $15 \AA$ and to determine the oligomeric number of the membrane protein. ${ }^{24-26}$ We also extended the heteronuclear dipolar-coupling technique, REDOR, to allow measurement of distances from the high-frequency ${ }^{1} \mathrm{H}$ spin to a low-frequency nucleus, so that distances as long as $\sim 8 \AA$ can be detected ${ }^{19,27,28}$ [Fig. 1(b)].

Static structure only gives partial insight into membrane protein function. Of equal importance is molecular motion [Fig. 1(c)]. Both global backbone motion $^{29-31}$ and local segmental motions ${ }^{6}$ are common in antimicrobial and CPPs due to the low molecular weights of these peptides and the fluidity of the lipid membrane. ${ }^{32}$ With increasing ability to detect motion by NMR, it is now recognized that even larger membrane proteins such as seven 


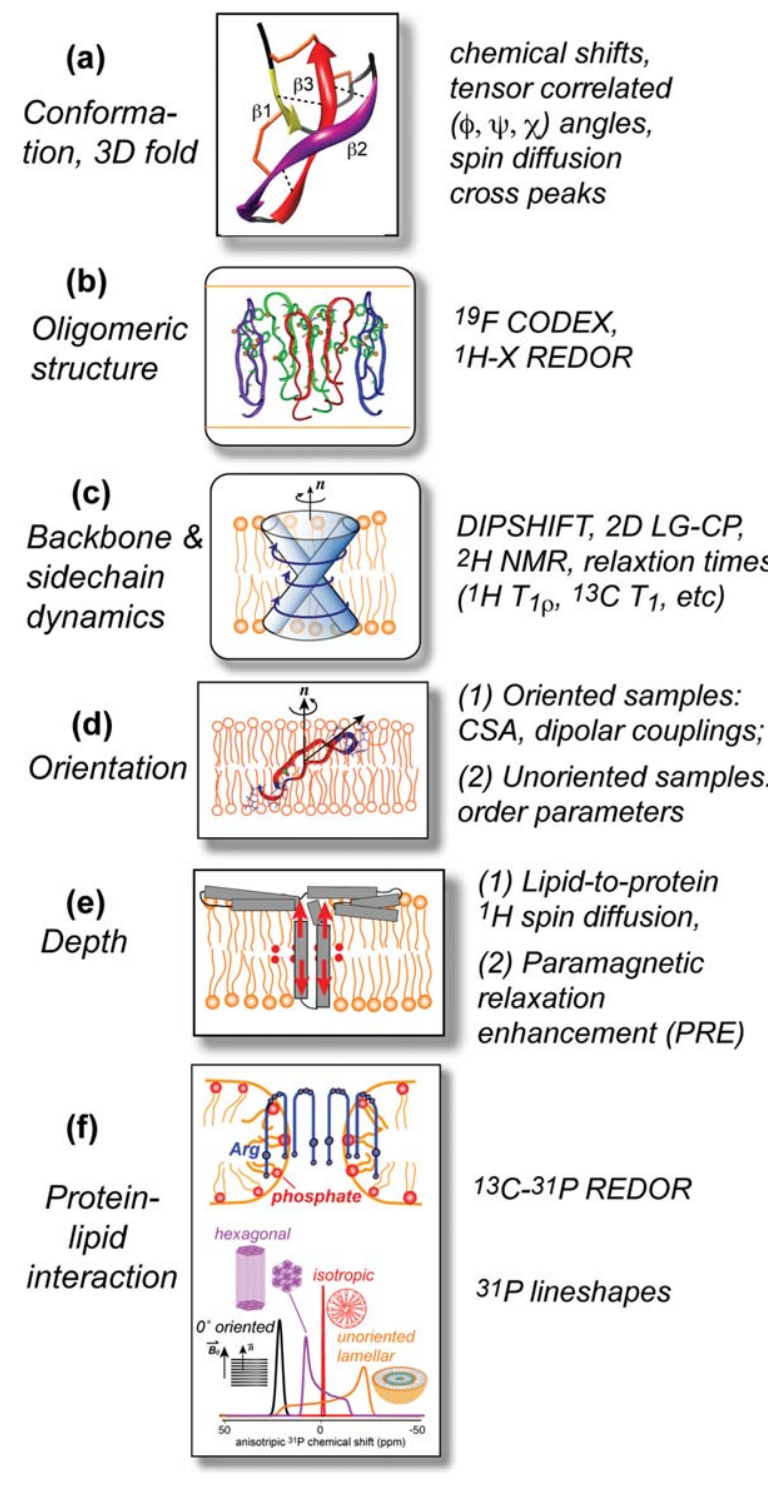

Figure 1. Summary of different types of membrane protein structural information that can be obtained from solid-state NMR. (a) Monomer conformation and 3D fold. (b) Oligomeric structure. (c) Protein dynamics. (d) Protein orientation in the membrane. (e) Depth of insertion. (f) Protein-lipid interactions.

transmembrane (TM)-helix proteins can undergo motions of sizeable amplitudes on the NMR timescale. ${ }^{33,34}$ Immobilization of a small polypeptide is usually a sign of its oligomerization in the membrane, whereas fast uniaxial rotational diffusion is usually associated with monomeric molecules and can disrupt lipid packing in the membrane. ${ }^{35}$ Motional effects manifest in NMR spectra as line narrowing for fast, submicrosecond, motions, exchange broadening for intermediate-timescale motions, and cross peaks between conformationally different states for slow millisecond motions. The most robust approach to detect fast motion by NMR is to measure one-bond $\mathrm{C}-\mathrm{H}$ and $\mathrm{N}-\mathrm{H}$ dipolar couplings using 2D separated local field experiments, ${ }^{36}$ which resolve the couplings of different sites according to their isotropic chemical shifts. Reduction of the couplings from their rigid-limit values by an order parameter $S$ indicates motion with an amplitude $\theta$ where $S \equiv\left\langle 3 \cos ^{2} \theta-1\right\rangle / 2$. To distinguish rigid-body motion from uncorrelated motion, one can measure whether multiple order parameters are correlated according to the protein conformation. For example, $\alpha$-helices that undergo rigid-body uniaxial rotation around the bilayer normal should exhibit backbone $\mathrm{N}-\mathrm{H}$ order parameters that fit to a periodic dipolar wave that depends on the tilt angle of the helix axis from the bilayer normal. ${ }^{31,37}$ This relationship between orientation and dynamics has been exploited to determine the orientation of several $\beta$-sheet AMPs. ${ }^{30,38}$ Local motions of protein side chains can reveal protein-lipid interactions. For example, the order parameters of the long side chain of Arg residues in the HIV TAT peptide was found to be the lowest in the middle and higher at the two ends, ${ }^{6}$ suggesting stabilization of the guanidinium ion by salt bridge interaction with the lipid phosphates.

Membrane proteins differ from globular proteins in that their structure has a topological component, that is, their orientation and depth of insertion in the lipid bilayer. Because of the orientation dependence of nuclear spin interactions, solid-state NMR gives precise information about protein orientation in the membrane. By aligning lipid membranes either mechanically using glass plates or magnetically using lipid bicelles, one can measure orientation-dependent NMR dipolar couplings and anisotropic chemical shifts to report the directions of the bonds from the magnetic field, which in turn reveal the orientation of the molecule from the bilayer normal [Fig. 1(d)]. ${ }^{39}$ Using this approach, and by identifying the so-called PISA wheel patterns in $2 \mathrm{D}^{15} \mathrm{~N}$ NMR spectra, ${ }^{40,41}$ we have determined the orientation of the voltage-sensing S4 helix of a potassium chancel in lipid bicelles. ${ }^{42}$ Although this oriented-sample approach is the mainstay of orientation determination by solid-state NMR, because of the dependence of the order parameters of uniaxially diffusing molecules on molecular orientation, one can now also determine protein orientation using unoriented liposomes. ${ }^{31,37}$ In this case, more straightforward MAS experiments can be applied and the sample preparation is much simpler. This unoriented sample approach has been demonstrated on a number of membrane peptides and their assemblies, ${ }^{30,31,37,43}$ due to the prevalence of uniaxial diffusion of small and medium membrane proteins.

To determine how deeply membrane proteins are immersed in the lipid bilayer at physiological temperature, we have adapted both lipid-to-protein spin diffusion ${ }^{44,45}$ and paramagnetic relaxation enhancement $(\mathrm{PRE})^{46}$ techniques [Fig. 1(e)]. ${ }^{47}$ The former correlates the ${ }^{1} \mathrm{H}$ signals of dynamic 
molecules in the membrane sample with ${ }^{13} \mathrm{C}$ signals of the protein after a ${ }^{1} \mathrm{H}$ spin diffusion period. The $\mathrm{CH}_{2}$ and $\mathrm{CH}_{3}$ signals of the lipid chains are particularly important as the ${ }^{1} \mathrm{H}$ magnetization source: TM proteins exhibit strong lipid-protein cross peaks in less than $100 \mathrm{~ms}$, whereas surface-bound peptides requires several hundred milliseconds and seconds to develop cross peaks. ${ }^{45}$ For immobilized membrane proteins, this ${ }^{1} \mathrm{H}$ spin diffusion technique gives semiquantitative depth information, because the diffusion coefficients of the lipid matrix and the lipidprotein interface can be estimated and calibrated. ${ }^{48}$ For peptides with comparable mobility to the lipids, distance extraction from ${ }^{1} \mathrm{H}$ spin diffusion is more difficult at ambient temperature, and the PRE technique provides a good alternative. $\mathrm{Mn}^{2+}$ or other paramagnetic ions bind to the negatively charged phosphate groups on the membrane surface and cannot freely penetrate into the membrane. ${ }^{47}$ These paramagnetic ions speed up nuclear spin relaxation in a distance-dependent fashion. Thus, by measuring the PREs of the peptide signals and compare them with those of the lipid carbons, whose depths are well known, one can obtain site-specific depths of the protein residues from the bilayer surface. ${ }^{47}$ Moreover, lipid vesicles for which only one surface of the bilayer is coated with $\mathrm{Mn}^{2+}$ can be prepared to determine the asymmetry of peptide insertion. ${ }^{49}$ For example, with outer-leaflet $\mathrm{Mn}^{2+}$-bound samples, peptides that insert only into the outer leaflet of the bilayer will exhibit stronger PRE effects (less residual intensity) than peptides that are distributed into both leaflets of the bilayer. Membrane protein depths can also be examined by measuring ${ }^{13} \mathrm{C}-{ }^{31} \mathrm{P}$ distances from the protein backbone to the lipid ${ }^{31} \mathrm{P}$, provided that the lamellar structure of the bilayer remains intact so that the positions of the ${ }^{31} \mathrm{P}$ atoms represent a well-defined membrane surface.

Finally, peptide-induced membrane disorder can be studied using ${ }^{31} \mathrm{P}$ NMR, which is highly sensitive to the membrane morphology. ${ }^{50}$ Lamellar fluid bilayers exhibit a characteristic uniaxial powder pattern of about $40 \mathrm{ppm}$ wide, while small vesicles or micelles exhibit an isotropic peak at 0 ppm [Fig. 1(f)]. Hexagonal-phase lipids have a twofold narrower uniaxial lineshape that is mirror symmetric with the lamellar powder pattern. Site-specific interactions between cationic residues and anionic lipid phosphates can be gleaned from side chain ${ }^{13} \mathrm{C}$ distances to lipid ${ }^{31} \mathrm{P}$ [Fig. 1(f)]. ${ }^{51}$ Water-protein $\mathrm{H}$-bonding, which may be involved in charge solvation, can be detected using $2 \mathrm{D}{ }^{13} \mathrm{C}-{ }^{1} \mathrm{H}$ and ${ }^{15} \mathrm{~N}-{ }^{1} \mathrm{H}$ correlation experiments. ${ }^{52}$

\section{Solid-State NMR Studies of AMPs}

AMPs are small and predominantly cationic peptides of the innate immune systems of many animals and plants. ${ }^{1,53,54}$ They kill a broad spectrum of microbes, from bacteria to fungi and even viruses, while possessing high selectivity between eukaryotic cells and microbial cells. AMPs as a family exhibit diverse secondary structures. Well-studied $\alpha$-helical AMPs include LL37 from humans, magainins from frogs, and cecropins from insects. ${ }^{1} \beta$-sheet rich AMPs usually contain one to four disulfide bonds. Examples include protegrins from pigs, tachyplesins from horseshoe crabs, and defensins from humans and other mammals. ${ }^{54}$ AMPs can also adopt random coil or turn conformations, such as indolicidins from cows and histatins from humans.

Based on the similar activities of D- and L-amino acid versions of AMPs, it is known that the principal mechanism of action of many AMPs is the destruction of the lipid-rich microbial cell membranes, ${ }^{55}$ because enzyme active sites cannot accommodate mirror images of peptides, whereas the dynamic lipid solvent is insensitive to protein chirality. The protective membranes of bacteria vary with the cell type. Gram-positive bacteria are coated by a thick (20-80 nm) but porous peptidoglycan layer ${ }^{56}$ and a 4-nm phospholipid bilayer, which is the main permeability barrier of the cell. Gram-negative bacteria are covered by an outer membrane rich in anionic and bulky lipopolysaccharides (LPS) and an inner cytoplasmic phospholipid bilayer. Both the LPS-rich outer membrane and the cytoplasmic membrane must be crossed and disrupted for AMPs to kill Gram-negative bacteria. ${ }^{57,58}$ In addition to phospholipid membranes, other targets of bacteria have also been found. These include bacterial cell wall precursors such as lipid $\mathrm{II}^{59,60}$ and outer-membrane proteins for cell wall biogenesis. ${ }^{61}$

For AMPs that disrupt phospholipid and LPS membranes, four main structural models have been proposed: barrel stave, toroidal pore, carpet, and inplane diffusion. ${ }^{53,62}$ The barrel-stave model, proposed based on studies of alamethicin, ${ }^{63,64}$ posits the formation of TM water-filled pores lined by the amphipathic peptides. Lipid molecules adopt their normal parallel orientation to the bilayer normal, with the acyl chains contacting the hydrophobic part of the amphipathic AMPs. In the carpet model, AMPs aggregate on the membrane surface; at sufficiently high concentrations, they thin the membrane and eventually micellize it. In the toroidal pore model, the peptides change the orientation of some lipid molecules so that the two leaflets merge. The resulting water-filled pore is lined by both peptides and polar lipid headgroups. ${ }^{65,66}$ Finally, the in-plane diffusion model posits that highly dynamic peptides undergo rotational diffusion in the membrane plane, causing transient defects that disrupt the barrier function. ${ }^{67}$

These mechanistic models provide readily testable hypotheses because the peptide orientation, depth of insertion, and dynamics differ significantly 
and can be accurately measured using SSNMR techniques described in "Solid-State NMR Techniques for Studying Protein-Membrane Interactions" section. Below we summarize the key structural results for several disulfide-bonded $\beta$-sheet-rich AMPs, which reveal the mechanistic diversity and common structural elements in this class of AMPs.

\section{Protegrin-1}

Protegrin-1 (PG-1) is a hexa-Arg 18-residue $\beta$-hairpin AMP constrained by two disulfide bonds (Fig. 2). It is derived from porcine leukocytes and has broadspectrum antimicrobial activities. ${ }^{57,68,69}$ The structure-activity relation of PG-1 has been explored extensively. ${ }^{70}{ }^{13} \mathrm{C}$ and ${ }^{15} \mathrm{~N}$ chemical shifts confirmed the $\beta$-strand conformation of the peptide in lipid membranes ${ }^{71,72}$ as in solution. ${ }^{73}$ Dipolar order parameters indicate that except for the short chain lipid DLPC (12:0), PG-1 is immobilized in lipid membranes with similar thickness as cell membranes, which contain 16- and 18-carbon chains. $^{71}$ As a monomeric 18-residue peptide should undergo fast rotational diffusion, ${ }^{32}$ PG-1 immobilization in the biologically relevant membrane thickness suggests extensive peptide oligomerization and possible formation of peptide-lipid supramolecular complexes. ${ }^{71}$

PG-1 also induces membrane disorder in a thickness-dependent manner: static ${ }^{31} \mathrm{P}$ NMR spectra of both oriented and unoriented samples showed strong isotropic peaks in POPX $(\mathrm{X}=\mathrm{C}, \mathrm{G}, \mathrm{E}) \mathrm{mem}$ branes but not DLPC membranes. ${ }^{72}$ The nonlamellar intensities increase with the concentrations of the peptide and the anionic lipids and decrease upon the addition of cholesterol. ${ }^{72,74}$ These trends correlate well with the selective disruption of anionic bacterial cell membranes. ${ }^{31} \mathrm{P} 1 \mathrm{D}$ and $2 \mathrm{D}$ exchange NMR, which are sensitive to millisecond lipid orientational changes, suggested that PG-1 slowed down the lipid lateral diffusion and reduced the average radius of curvature of $\mathrm{POPC}$ vesicles by threefold, ${ }^{75}$ implying that the membrane is fragmented to smaller vesicles or formed curved morphologies such as toroidal pores within the bilayer.

The depth and orientation of PG-1 were determined in intact DLPC bilayers using $\mathrm{Mn}^{2+}$ PRE experiments. ${ }^{47}$ The two long ends of the elongated molecule experienced stronger $\mathrm{T}_{2}$ relaxation enhancements, whereas residues in the middle of the hairpin are more shielded from the $\mathrm{Mn}^{2+}$ effects. Thus, PG-1 spans both leaflets of the DLPC bilayer. $^{47}$ Comparison with the lipid PREs further suggested that the DLPC bilayer was thinned by 8-10 А by PG-1. As DLPC bilayers are already thinner than POPX bilayers, the result suggests even more severe mismatch with POPX membranes, which may drive the formation of large-scale defects. ${ }^{72,74}$ The PG-1 depth was corroborated by orientation measurements. The ${ }^{13} \mathrm{CO}$ chemical shift
PG-1

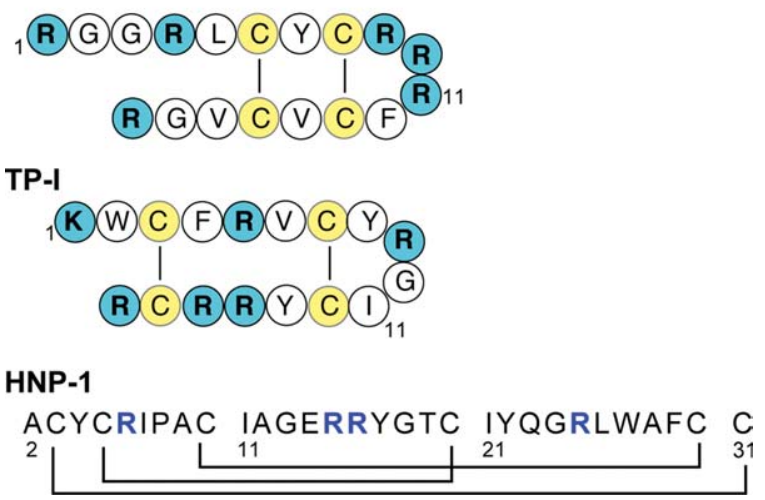

Figure 2. Amino acid sequence of three disulfide-stabilized $\beta$-sheet AMPs.

tensor in a $\beta$-strand is highly sensitive to the orientations of the $\beta$-sheet axis and plane. The ${ }^{13} \mathrm{CO}$ and ${ }^{15} \mathrm{~N}$ chemical shift anisotropies (CSAs) of glass-platealigned PG-1 in DLPC bilayers corresponded to a tilt angle of $55^{\circ}$ for the $\beta$-strand axis. Thus, the $30-\AA$ long peptide projects a hydrophobic length of $\sim 17 \AA$ onto the bilayer normal, which is comparable with the hydrophobic thickness of the DLPC bilayer. The fact that PG-1 is not more upright may be due to the distribution of the Arg molecules; a tilted $\beta$-sheet would better allow snorkeling of the Arg side chains to the two membrane surfaces than an upright $\beta$-sheet.

In POPX membranes, PG-1 is immobilized, suggesting aggregation. The precise oligomeric structure was examined using ${ }^{19} \mathrm{~F}$ spin diffusion and REDOR experiments. In the anionic bacteria-mimetic POPE/POPG membrane, ${ }^{1} \mathrm{H}_{-}{ }^{13} \mathrm{C}$ and ${ }^{13} \mathrm{C}-{ }^{19} \mathrm{~F}$ REDOR data indicated that the $\beta$-hairpins align in parallel with two C-terminal strands in H-bonding distance of each other. ${ }^{76}{ }^{19} \mathrm{~F}$ spin diffusion data confirmed this result and further showed that the $\mathrm{N}$ terminal strands also pack together but more loosely. Each ${ }^{19} \mathrm{~F}$ label existed in a two-spin cluster within the $15-\AA$ upper limit of the technique. ${ }^{77}$ Thus, the basic unit of PG-1 assembly is a NCCN dimer, which further associates into a ...NCCNNCCN. . . oligomer that likely wraps onto itself to form a $\beta$-barrel. Leakage assays suggested an inner diameter of about 20 $\AA$ for PG-1 formed pores, delineating the size of the $\beta$-barrel. Lipid-protein ${ }^{1} \mathrm{H}$ spin diffusion indicates that the $\beta$-barrel is TM, in close contact with the lipid chains [Fig. 3(a)].

In eukaryote-mimetic POPC/cholesterol membranes, the topology and oligomeric structure of PG1 differ dramatically from the anionic membrane situation. The peptide forms at least tetramers, which are no longer inserted into the membrane, as manifested by slow ${ }^{1} \mathrm{H}$ spin diffusion from the lipid chains. $^{77}$ Thus, PG-1 is prevented from inserting into the cholesterol-rich host cell membranes due to 
(a)
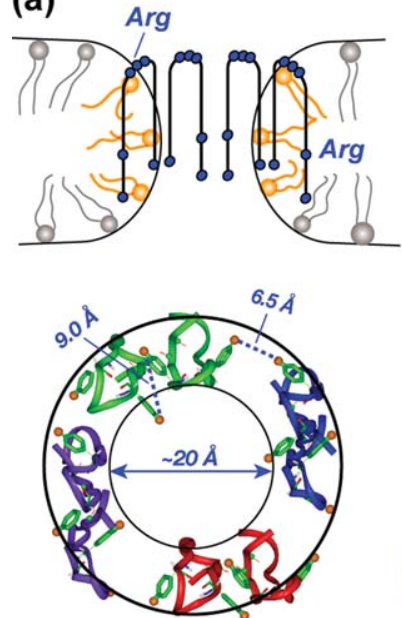

(b)
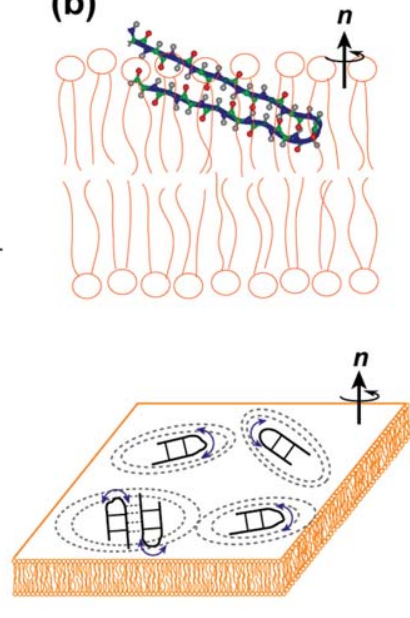

(c)
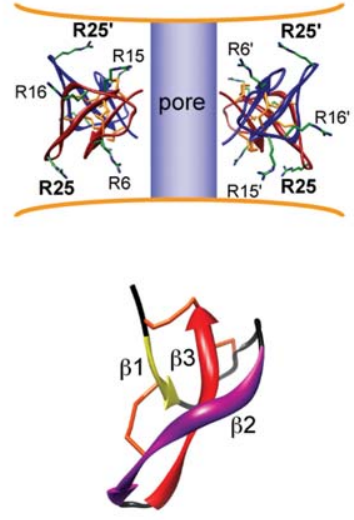

(d)
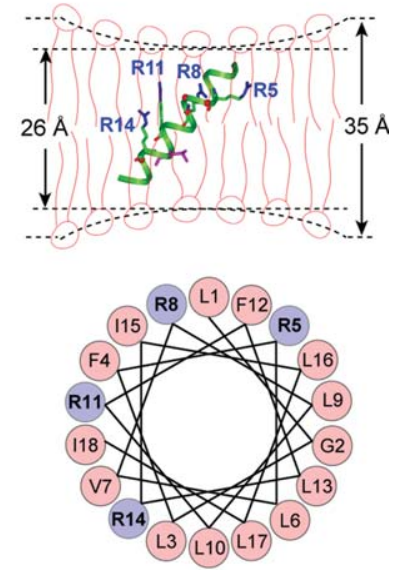

Figure 3. The topology of Arg-rich membrane peptides reveals their mechanisms of action. The side views of the peptide structure and topology in the membrane are shown in the top row, whereas the bottom row shows either the peptide structure motif or the top view of the membrane-bound topology. (a) PG-1 forms TM $\beta$-barrels that cause toroidal pore defects in POPE/POPG membranes. Four to five PG-1 dimers comprise the barrel, which has an inner diameter of $\sim 20 \AA$. (b) TP-I binds to the interface of anionic lipid membranes and undergoes fast uniaxial diffusion to cause membrane defects. (c) HNP-1 dimers form TM pores where each dimer is oriented with the hydrophobic basket bottom facing the lipids and the hydrophilic top facing the pore. R25 is closest among the four Arg residues to the membrane surface. The monomer structure as determined by solid-state NMR is shown at the bottom. (d) The S4 helix of the KvAP voltage-sensing domain is inserted across the membrane with a $40^{\circ}$ tilt angle and thins the membrane to stabilize the gating Arg molecules. The distribution of the Arg residues is shown in the helical wheel diagram at the bottom.

the membrane rigidity and negative curvature imparted by cholesterol.

The lipid structure around the PG-1 $\beta$-barrels in the POPE/POPG membrane was probed using ${ }^{13} \mathrm{C}-{ }^{31} \mathrm{P}$ REDOR experiments. ${ }^{51}$ For the first time, short Arg C $\zeta-\mathrm{P}$ distances (4.0-5.7 $\AA$ ) were found, indicating $\mathrm{H}$-bonding of the guanidinium with the phosphates. This short distance was true even for an Arg residue in the middle of the TM $\beta$-strand. Combined with the fact that two consecutive residues in the middle of the $\mathrm{N}$-terminal strand have the same short $\mathrm{C} \alpha-\mathrm{P}$ distances $(6.5 \AA)$, these results indicate that the local ${ }^{31} \mathrm{P}$ plane is parallel to the TM $\beta$-hairpin, which means that some lipid head groups are embedded in the hydrophobic part of the membrane, which is precisely the signature of the toroidal pore morphology ${ }^{66,78}$ [Fig. 3(a)].

We further probed the nature of the guanidinium-phosphate interaction by mutating the Arg molecules to dimethylated Arg molecules $\left(\mathrm{Arg}^{\mathrm{mm}}\right)$, which removed two possible H-bond donors. ${ }^{30}$ If electrostatic attraction is the only factor causing the Arg-phosphate interaction, then dimethylation should have no effect on PG-1 structure and activity. Instead, Arg ${ }^{\mathrm{mm}}$-PG-1 has threefold weaker antimicrobial activities and has significantly altered structure in the membrane ${ }^{30}$ : it is uniaxially mobile and thus no longer highly oligomerized in the membrane. Based on backbone order parameters, we determined the orientation of $\mathrm{Arg}^{\mathrm{mm}}-\mathrm{PG}-1$ : it "slices" into the membrane like a knife, with the $\beta$-strand axis roughly perpendicular to the bilayer normal. ${ }^{30}$ This dynamic "molecular knife" motif may explain the partial retention of the antimicrobial activity, since it has been found in other antimicrobial molecules. ${ }^{43}$ Thus, H-bonding indeed contributes to stabilization of the guanidinium-phosphate complex.

The sequence dependence of PG-1 structure in the membrane has been examined. The disulfide bonds are important in so far as it maintains the amphipathic structure of the $\beta$-hairpin. Removal of the disulfide bonds by Cys-Ala mutations yielded a random coil peptide that no longer disrupted the lipid membrane. ${ }^{79}$ Decreasing the Arg density weakened the antimicrobial activity ${ }^{70}$ and caused a mutant that no longer inserted fully into anionic membranes, in contrast to the wild-type peptide. ${ }^{80}$

We recently also investigated the interaction of PG-1 and a charge-reduced mutant with LPS-rich membranes versus regular phospholipid membranes. ${ }^{81}$ Although PG-1 is active against both Grampositive and Gram-negative bacteria, the chargereduced mutant is inactive against Gram-negative bacteria, which contain the LPS-rich outer membrane. Depth measurements indicate that PG-1 spans the LPS-rich membrane and causes TM pores without lipid orientational change. These pores may allow a conduit for more peptide to cross into the cytoplasmic membrane to kill the cells. In comparison, the chargereduced mutant is only partially inserted in the LPSrich membrane, thus accounting for its inactivity against Gram-negative bacteria. 


\section{Tachyplesin-I}

Tachyplesin I (TP-I) is a horseshoe crab-derived $\beta$ hairpin AMP with an analogous sequence to PG-1. ${ }^{82}$ The main difference lies in the distribution of the Arg residues: they are interspersed with the hydrophobic residues in TP-I but segregated from the nonpolar ones in PG-1 (Fig. 2). ${ }^{12}{ }^{31} \mathrm{P}$ spectra of samples aligned on glass plate showed sensitive dependence of the TP-I-induced disorder on the membrane composition: the peptide caused no disorder to POPC/ POPG (3:1) bilayers but both isotropic and powder intensities in POPE/POPG samples. ${ }^{83}$ As POPE is the main zwitterionic lipid in bacteria membranes and has a smaller headgroup than POPC, this selective disordering is consistent with the peptide activity and suggests the role of curvature induction in TP-I action.

Unlike PG-1, we directly measured and confirmed the $\beta$-hairpin structure of TP-I to address inconsistent prior solution NMR results that showed the $\mathrm{N}$ - and C-terminal chains to be straight $\beta$ strands at low DPC concentrations but curved in the middle of each strand at high DPC concentrations. ${ }^{84}$ In DMPC/DMPG bilayers, the $(\phi, \psi)$ torsion angles of Val6 were measured using dipolar correlation experiments and were found to be $\left(-133^{\circ}, 142^{\circ}\right)$, whereas Cys7 $(\phi, \psi)$ angles were determined through a Val6 ${ }^{13} \mathrm{CO}-\mathrm{Phe} 8{ }^{15} \mathrm{~N}$ distance to also correspond to the $\beta$-strand conformation. ${ }^{85}$ Thus, the $\mathrm{N}$-terminal chain adopts ideal $\beta$-strand conformation without a kink, supporting the low-DPC bound structure. For comparison, the Gly10 $\phi$ angle was $85^{\circ}$ or $-85^{\circ}$, confirming its $i+2$ position in the $\beta$-turn tip.

How is TP-I inserted into the anionic lipid membrane? The backbone ${ }^{13} \mathrm{C}$ distances to ${ }^{31} \mathrm{P}$ were measured to be $\sim 7 \AA$, and peptide cross peaks with lipid $\mathrm{CH}_{2}$ did not reach plateau within $100 \mathrm{~ms}$ but continued to grow at longer mixing times. ${ }^{85}$ Thus, TP-I is partially inserted into the anionic lipid membrane [Fig. 3(b)], which differs from PG-1 and suggests that the interspersed nature of the basic and hydrophobic residues limits TP-I insertion. In this way, the Arg residues may be stabilized in the intermediate dielectric environment of the membranewater interface.

To understand how the partially inserted TP-I achieves its antimicrobial activity, we compared its structure and dynamics with two Cys mutants with different activities: TPF4, where all four Cys molecules were mutated to Phe, was similarly active as TP-I, whereas TPA4 has much weaker activities. We found that the active TPF4 and the inactive TPA4 both adopt a straight $\beta$-strand conformation without a turn, and TPA4 has similar insertion depth as TPI. Thus, neither conformation nor depth correlates with the activity profile of the three peptides. ${ }^{35}$ Instead, the mobility profile does. The active TP-I and TPF4 both show fast segmental and global motions in the membrane, whereas TPA4 is immobilized. These dynamic differences were observed from temperature-dependent ${ }^{13} \mathrm{C}$ intensities, motionally averaged couplings, and spin relaxation times. ${ }^{35}$ These data suggest that TP-I and TPF4 disrupt the lipid membrane by in-plane diffusion, where the interfacial-located peptides diffuse around the bilayer normal to cause membrane defects. ${ }^{35}$ [Fig. 3(b)]. In comparison, TPA4 is immobilized by aggregation and lies on the membrane surface, which is the first stage in the carpet model of antimicrobial activity. The relative activities thus suggest that the in-plane diffusion mechanism is more effective in disrupting lipid membranes than the carpet mechanism, because the latter requires a higher amount of peptides.

\section{Human $\alpha$-defensin}

Defensins are larger disulfide-bonded AMPs than PG-1 and TP-I; they typically contain three $\beta$ strands linked by short segments of other secondary structures. Depending on their disulfide linkage patterns, defensins are categorized into $\alpha-, \beta-$, and $\theta$ families. ${ }^{54}$ Humans have six $\alpha$-defensins, whose crystal structures have been solved in the absence of lipid-mimetic solvents. ${ }^{86,87}$ The proteins crystallize into basket-shaped dimers with a polar top and a nonpolar base. Based on this structure, several membrane-binding models were proposed, including wedge, dimer pore, general pore ${ }^{86}$ and multimeric pore. ${ }^{88}$ Recently, methods for recombinant expression of correctly folded defensins became available, ${ }^{89}$ facilitating high-resolution structural studies of these proteins in membrane-mimetic environments.

We carried out full structure determination of one of the six human $\alpha$-defensins, HNP-1, using multidimensional solid-state NMR of uniformly ${ }^{13} \mathrm{C}$, ${ }^{15} \mathrm{~N}$-labeled protein. ${ }^{22}$ Experiments on microcrystalline, lipid-free, HNP-1 were conducted to resolve and assign all protein signals. Two-dimensional and three-dimensional correlation experiments, now standard in MAS NMR, ${ }^{90,91}$ allowed the full assignment of HNP-1 resonances. Three-dimensional ${ }^{13} \mathrm{C}-{ }^{13} \mathrm{C}-{ }^{13} \mathrm{C}$ correlation spectra then provided the crucial inter-residue distances to constrain the 3D fold $^{92}$ [Fig. 3(c)]. The NMR structure not only showed the same disulfide-constrained fold as the crystal structures but also indicated differences from HNP $-3^{86}$ in the conformation of the rigid loop connecting the first and second $\beta$-strands. ${ }^{22}$ This loop conformation is also variable among different defensin crystal structures, suggesting it may be caused by sequence differences among $\alpha$-defensins. ${ }^{22}$

On reconstitution into DMPC/DMPG bilayers, HNP-1 exhibited much broader line widths, indicating lipid-induced conformational heterogeneity. But the peak positions remain largely unchanged from 
the microcrystalline state, indicating that the average conformation of the protein is unperturbed by lipid binding, which is expected for this disulfide-stabilized protein. ${ }^{23}$ The main exception is the R25 and I21 in the turn between the second and third $\beta$ strands, whose side chain signals became stronger in the membrane-bound state, suggesting immobilization by membrane binding. In contrast to the smaller PG-1 and TP-I, HNP-1 caused little membrane orientational disorder. ${ }^{1} \mathrm{H}$ spin diffusion from the lipid chains to the protein is rapid, indicating that HNP-1 inserts across the membrane in a TM fashion, which rules out the wedge model. Analysis of ${ }^{13} \mathrm{C}-{ }^{31} \mathrm{P}$ distances for the four Arg molecules and the water-protein ${ }^{1} \mathrm{H}$ spin diffusion profile led to the conclusion that the HNP-1 dimer is oriented with the hydrophobic basket bottom facing the lipids and the polar top facing the aqueous pore, such that R25 is the closest Arg to the membrane surface ${ }^{31} \mathrm{P}^{23}$ [Fig. 3(c)]. This topology explains the R25 immobilization seen in the $2 \mathrm{D}{ }^{13} \mathrm{C}$ correlation spectrum. The aqueous pore thus formed by the membrane-spanning protein should depolarize the bacterial cell. Recent reports also suggest that HNP-1 may interact with bacterial cell wall precursors such as lipid $\mathrm{II}^{60}$ to achieve its antimicrobial function.

\section{Cell-Penetrating Peptides}

\section{Biological activities}

Efficient intracellular delivery of bioactive molecules such as proteins, DNA, and nanoparticles is therapeutically important but difficult to achieve due to the impermeable nature of cell membranes. CPPs, also called protein transduction domains, are a family of small and highly cationic peptides that are readily internalized into cells while tethered to large macromolecular cargos by electrostatic interactions or covalent bonds (Fig. 4). ${ }^{2,93-95}$ Two of the most studied CPPs are the transactivating transcriptional activator (TAT) of HIV-1 virus ${ }^{96,97}$ and the penetratin peptide of the Antennapedia homeodomain of Drosophilia. ${ }^{98}$ Other protein-derived or chemically synthesized CPPs such as polyarginines have also been characterized. ${ }^{99,100}$ Because of the highly charged nature of CPPs, the same free-energy question for AMPs is also relevant for CPPs. Structural studies of CPPs when bound to lipid membranes thus provide valuable insights into their mechanism of membrane translocation. We summarize below our SSNMR findings of penetratin and HIV TAT.

\section{Dynamic and unstructured nature of membrane-bound CPPs}

In contrast to AMPs, which mostly have well-defined and amphipathic structures, neither penetratin nor HIV TAT exhibit canonical secondary structures in the lipid bilayer. TAT was already known to exist as

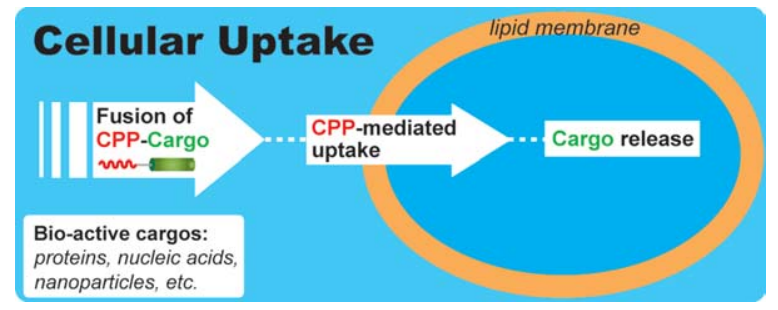

Figure 4. CPP-mediated intracellular delivery of therapeutic cargos.

a random coil in aqueous and organic solutions ${ }^{101}$; nevertheless, its random conformation in the lipid bilayer was surprising, ${ }^{6}$ because many peptides acquire H-bonded secondary structures on membrane binding. ${ }^{102}$ The conformation of penetratin was known to depend on the environment; it is random coil in water, $\alpha$-helical in SDS micelles, ${ }^{103}$ and $\alpha$-helical, random coil or $\beta$-sheet in lipid-mimetic solvents depending on the thickness and anionic content of the membrane. ${ }^{104-106}$

Chemical shifts indicate that in anionic bilayers, penetratin conformation depends on the temperature; in the gel phase the peptide exhibits $\beta$-sheet ${ }^{13} \mathrm{C}$ and ${ }^{15} \mathrm{~N}$ shifts while at physiological temperature it exhibits coil or turn chemical shifts. ${ }^{107}$ This unusual sheet $\rightarrow$ coil conformational change occurs in saturated DMPC/DMPG and unsaturated POPC/ POPG membranes, is reversible with temperature, and occurs at a range of peptide/lipid molar ratios. Thus, it is an intrinsic property of the peptide. Analysis of the peak intensities of the two states indicated that the sheet $\rightarrow$ coil transition is entropically driven; a positive enthalpy change of $+0.89 \mathrm{kcal} / \mathrm{mol}$ is countered by a positive entropy change of +3.1 $\mathrm{cal} /(\mathrm{mol} \mathrm{K}){ }^{107}$ At high temperature, the backbone exhibits low order parameters of $0.23-0.52 .{ }^{107} \mathrm{How}-$ ever, among five examined residues, one residue, Arg10, retained the $\beta$-strand torsion angles at high temperature and exhibited a nearly rigid-limit $\mathrm{C} \alpha$ $\mathrm{H} \alpha$ order parameter $\left(S_{\mathrm{CH}}=0.92\right) .{ }^{108}$ This difference suggests that Arg molecules, due to their interactions with lipid phosphates, may stabilize the conformation of the otherwise coil or turn-rich penetratin.

The dynamic structure is even more pronounced for membrane-bound HIV TAT. ${ }^{6}$ Not only do TAT chemical shifts correspond to the random coil conformation but also the line widths are extremely narrow at high temperature $\left(\sim 0.3 \mathrm{ppm}\right.$ for $\left.{ }^{13} \mathrm{C}\right)$ and broadened $\left(\sim 4.5 \mathrm{ppm}\right.$ for $\left.{ }^{13} \mathrm{C}\right)$ to include a large range secondary shifts at low temperature. This random coil conformation was corroborated by extremely low backbone order parameters (0.140.20 ) and the resolution of ${ }^{1} \mathrm{~J}_{\mathrm{CH}}$ couplings in $2 \mathrm{D}$ ${ }^{1} \mathrm{H}-{ }^{13} \mathrm{C}$ correlation spectra measured without ${ }^{1} \mathrm{H}$ homonuclear decoupling. Thus, HIV TAT is arguably the first clear documented case of a membranebound random coil peptide. The fact that both 
penetratin and HIV TAT are highly dynamic and unstructured suggests that this state may be relevant for membrane translocation, which is supported by other data summarized below.

\section{Depth of insertion of CPPs and weak membrane perturbation}

To understand how the cationic CPPs cross the lipid membrane, we measured the insertion depths using PRE, ${ }^{13} \mathrm{C}-{ }^{31} \mathrm{P}$ REDOR, and ${ }^{1} \mathrm{H}$ spin diffusion experiments. One-side PRE was developed to determine both the depth and symmetry of penetratin insertion in liquid-crystalline membranes ${ }^{49}$ [Fig. 5(a,b)]. An electroporation model had suggested that at low concentrations CPPs bind to the outer leaflet of the bilayer, causing a TM electric field that alters membrane curvature. At sufficiently high concentrations, electroporation-like membrane permeabilization occurs, driving peptide translocation and relieving the curvature stress. ${ }^{109}$ The $\mathrm{T}_{2}$ PREs of outer-surface $\mathrm{Mn}^{2+}$ indicate that penetratin retains more than $60 \%$ of the intensity at $\mathrm{P} / \mathrm{L}=1: 40$, thus the peptide is distributed in both leaflets of the bilayer already at low concentrations. ${ }^{49}$ The peptide backbone exhibits ${ }^{13} \mathrm{C}-{ }^{31} \mathrm{P}$ distances $6.9-8.2 \AA$, indicating an interfacial location. Therefore, penetratin is inserted into both leaflets of the bilayer but is far from the membrane center [Fig. 5(c)]. The one-side PRE technique was also recently applied to an antimicrobial arylamide to reveal its interfacial binding. 43

${ }^{1} \mathrm{H}$ spin diffusion was used to measure the depth of HIV TAT in DMPC/DMPG bilayers. ${ }^{6}$ Although mobile peptides generally do not lend themselves well to quantitative depth extraction using this technique, due to the difficulty of estimating the diffusion coefficients, qualitative depth information can still be obtained based on the observation of lipidpeptide cross peaks. TAT exhibited strong water cross peaks and, despite its nearly isotropic mobility and hence inefficient spin diffusion, weak but clear lipid-chain cross peaks with the peptide were observed within a short mixing time of $144 \mathrm{~ms}$. Thus, the peptide is bound inside the membrane, likely in the glycerol backbone region [Fig. 5(d)]. Indeed, TAT binding enhanced ${ }^{1} \mathrm{H}$ spin diffusion from water to the lipid head groups in POPE/POPG membranes, also ruling out an external surface location. All polar residues with exchangeable protons such as Lys4, Gln7, and Arg8 showed strong water cross peaks, indicating stabilization of the charged residues by peptide-water interactions.

Static ${ }^{31} \mathrm{P}$ NMR line shapes showed that, in contrast to PG-1 and TP-I, penetratin and TAT did not create isotropic or hexagonal phase peaks, but only increased the powder intensities in glass-plate aligned samples. ${ }^{43,49}$ Static ${ }^{2} \mathrm{H}$ spectra showed no changes in the ${ }^{2} \mathrm{H}$ quadrupolar splittings of the lipid (a)
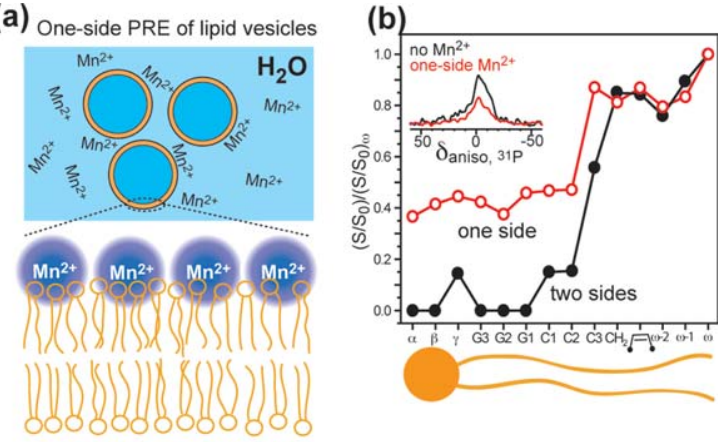

(c)

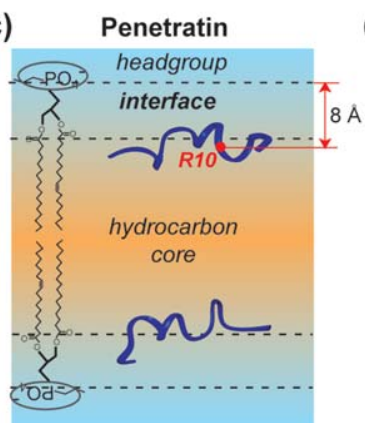

(d)

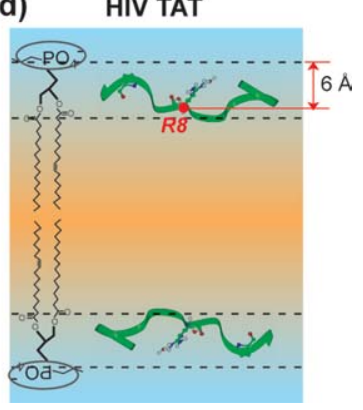

Figure 5. Depth of insertion of CPPs. (a) One-side PRE of large unilamellar vesicles. Orange: lipids. Blue: water. $\mathrm{Mn}^{2+}$ ions are distributed only on the outer surface of the lipid vesicles. (b) Double normalized intensity of $\mathrm{Mn}^{2+}$-bound POPC/POPG membranes. ${ }^{31} \mathrm{P}$ intensities are roughly halved in a one-side $\mathrm{Mn}^{2+}$ sample (inset) as expected. Carbons more embedded in the membrane experience less $T_{2}$ relaxation enhancement and thus exhibit higher intensities. Red: one-side $\mathrm{Mn}^{2+}$-bound samples. Black: two-side $\mathrm{Mn}^{2+}$ bound samples. (c) Depth of penetratin in POPC/POPG membranes $(P / L=1: 15)$ from one-side PRE and ${ }^{13} \mathrm{C}-{ }^{31} \mathrm{P}$ distances. ${ }^{49}$ (d) Depth of HIV TAT in DMPC/DMPG membranes $(P / L=1: 15)$ from ${ }^{1} \mathrm{H}$ spin diffusion and ${ }^{13} \mathrm{C}-{ }^{31} \mathrm{P}$ distances. ${ }^{6}$

acyl chains on peptide binding. Therefore, the lamellar order of the lipid membrane was intact, consistent with the generally nondisruptive nature of CPPs.

\section{Different roles of Arg and Lys in membrane translocation}

Penetratin and HIV TAT contain 38 and $62 \%$ cationic residues, respectively (Table I), and thus are ideal for studying the roles of Arg and Lys in membrane translocation. Figure 6 summarizes key ${ }^{13} \mathrm{C}-{ }^{31} \mathrm{P}$ distances measured in the two peptides. ${ }^{6,108}$ Penetratin exhibits short side chain ${ }^{13} \mathrm{C}-{ }^{31} \mathrm{P}$ distances of 4.2 and $4.0 \AA$ from $\operatorname{Arg} 10 \mathrm{C} \zeta$ and Lys13 $\mathrm{C} \varepsilon$, respectively, whereas the neutral side chains of Ile3 has much longer distances. ${ }^{108}$ Therefore, short ${ }^{13} \mathrm{C}-{ }^{31} \mathrm{P}$ distances are specific to cationic side chains due to charge neutralization and $\mathrm{H}$-bonding.

It is well documented that CPP analogs where Arg molecules were replaced by Lys molecules have lower translocation efficiencies. ${ }^{111}$ For example, the uptake efficiency of an all-Arg analog of penetratin 
(a) arginine

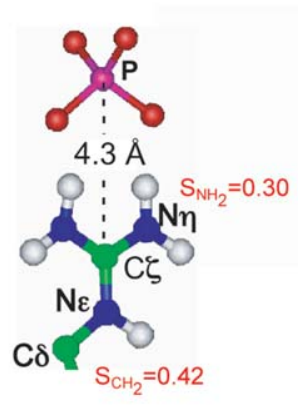

(b) lysine

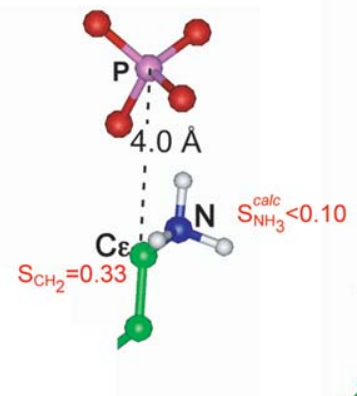

(c) isoleucine

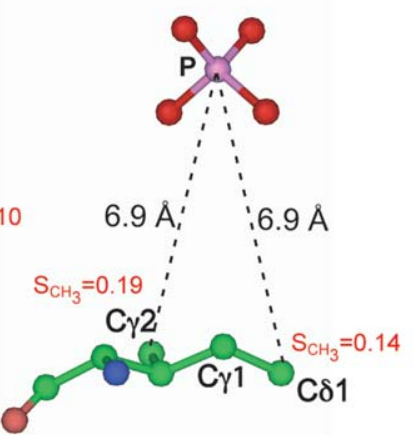

(d) arginine

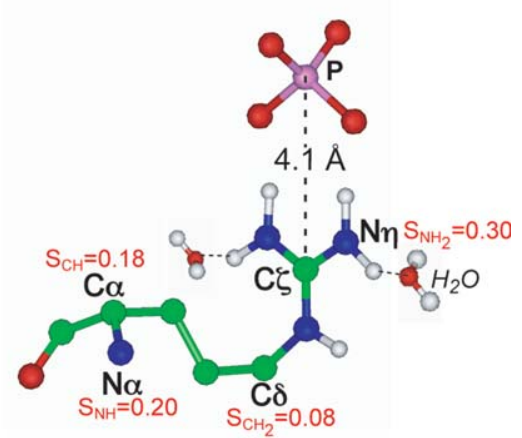

Figure 6. ${ }^{13} \mathrm{C}-{ }^{31} \mathrm{P}$ distances and order parameters of several residues in membrane-bound penetratin (a-c) and TAT (d). (a) Arg10 C $\zeta-P$ distance in DMPC/DMPG-bound penetratin. (b) Lys13-phosphate distance in DMPC/DMPG bound penetratin. (c) Longer lle ${ }^{13} \mathrm{C}-{ }^{31} \mathrm{P}$ distances in penetratin indicate no interaction between neutral residues and lipid headgroups. (d) Guanidinium-phosphate and guanidinium-water interactions of Arg8 in DMPC/DMPG bound TAT. All distances were measured in gel-phase membranes while dipolar order parameters were measured in the liquid-crystalline phase.

was higher than the wild-type peptide, which contains three Arg molecules and four Lys molecules, whereas an all-Lys analog had lower translocation abilities. ${ }^{111}$ Thus, the similarly short ${ }^{13} \mathrm{C}-{ }^{31} \mathrm{P}$ distances of Arg10 and Lys13 side chains were at first puzzling. However, these distances were measured in the gel-phase membrane to freeze lipid motions. In the fluid phase, Arg10 guanidinium exhibited much higher order parameters $\left(S_{\mathrm{NH}}=0.3\right)$ than the Lys13 ammonium $\left(S_{\mathrm{NH}}<0.1\right)$, indicating that the Lys-phosphate interaction is weaker at physiological temperature where membrane translocation occurs, due to the mobility of the ammonium group and the poorly directed nature of its $\mathrm{H}$-bonds.

Similarly, short Arg8 $\quad \mathrm{C} \zeta_{-}{ }^{31} \mathrm{P}$ distance was detected for HIV TAT in DMPC/DMPG bilayers [Fig. 6(d)]. ${ }^{6}$ Interestingly, the guanidinium-phosphate interaction caused a nonmonotonic order parameter profile of the side chain; the order parameters decreased from $\mathrm{N} \alpha\left(S_{\mathrm{NH}}=0.20\right)$ to $\mathrm{C} \delta\left(S_{\mathrm{CH}}=0.08\right)$ and then increased to $\mathrm{N \eta}\left(S_{\mathrm{NH}}=0.30\right)$, thus confirming the presence of stabilizing salt bridge interactions.

\section{Free energy of CPP insertion into lipid membranes}

The classical Wimley-White interfacial scale has been used to estimate the free energy of transferring an amino acid from water to the membrane-water interface. ${ }^{112}$ Based on this scale, the insertion of TAT from water to the membrane-water interface would require a high energy of $\sim 9 \mathrm{kcal} / \mathrm{mol}$. However, the actual energy barrier for TAT binding to anionic membranes is almost certainly much lower, because the Wimley-White interfacial scale was derived for neutral POPC bilayers and thus does not include electrostatic attraction between cationic peptides and anionic lipids. Indeed, calorimetric studies of the binding energy of HIV TAT to $25 \%$ anionic membranes ${ }^{113,114}$ reported a favorable free energy of $-5.2 \mathrm{kcal} / \mathrm{mol}$ and $80 \%$ of which was estimated to be due to electrostatic interaction. In addition to electrostatic attraction, H-bonding of the guanidinium ions to the lipid phosphates and water, as detected in the NMR spectra, ${ }^{6}$ must further contribute to the stabilization of TAT at the membrane-water interface. Each guanidinium ion can form up to five $\mathrm{H}$ bonds with lipid phosphates and water. Thus the hexa-Arg TAT could gain up to $-15 \mathrm{kcal} / \mathrm{mol}$ favorable free energy. ${ }^{107}$ We hypothesize that these two contributions overcome the Born repulsion and account for the facile insertion of this highly charged peptide into the lipid membrane.

\section{Mechanism of CPP translocation}

Much of the debate about the mechanism of action of CPPs centers on whether cellular uptake proceeds via direct membrane crossing, endocytosis, or other transient vesicle-mediated routes. The endocytosis mechanism was proposed based on the observation that cellular uptake of CPPs in living cells is temperature and energy-dependent ${ }^{115}$; however such temperature sensitivity should also occur in membrane-mediated cellular uptake. Even if the endocytotic pathway is operative, a CPP may still need to cross the endosomal membrane to enter the cytoplasm. An earlier inverse micelle model ${ }^{116}$ can be ruled out by the lack of isotropic signals in static ${ }^{31} \mathrm{P}$ NMR spectra. ${ }^{49}$ A membrane-crossing mechanism for CPPs was supported by MD simulations ${ }^{8,117}$ and by the solid-state NMR data summarized here. The CPP interaction with lipids is unique in many ways among membrane peptides. The high cationic density has several consequences. First, it drives CPP binding to the membrane surface, ${ }^{113,114}$ after which Arg-phosphate interactions facilitate peptide 
insertion into the membrane by minimizing the exposure of the charged residues to the hydrophobic interior. Second, the Arg clusters can strongly interact with lipid headgroups on the distal surface of the bilayer to drive translocation. Third, the high charge density removes any amphipathic structure, thus, preventing the peptide from forming long-lasting supramolecular complexes with lipids that would prevent its further entry into the cell. The unstructured CPPs stabilize their backbone polar groups by forming transient intermolecular $\mathrm{H}$-bonds with the lipid phosphates and water. ${ }^{6}$ Thus, the much higher conformational dynamics and the unstructured nature of TAT and penetratin compared with most AMPs are likely functionally relevant and distinguish them from AMPs, which seemingly have similar amino acid sequences.

\section{Arg-Rich Voltage-Sensing Helix of a Potassium Channel}

The opening and closing of voltage-gated potassium channels are controlled by several conserved Arg residues at every third position in the S4 helix of the voltage-sensing domain (VSD). ${ }^{118,119}$ The interaction of these Arg molecules with the lipid membrane has been of strong interest for understanding the atomic mechanisms of voltage-gated ion channels. A paddle model based on the crystal structure suggested that the gating Arg molecules interact directly with the lipids, ${ }^{3}$ whereas the canaliculi model proposed that the Arg molecules were shielded by acidic residues in other TM helices of the VSD. ${ }^{120}$

We determined the orientation and insertion depth of a peptide corresponding to the S4 helix of a potassium channel, KvAP, in lipid bilayers using both oriented-sample and MAS NMR. ${ }^{42}$ Two-dimensional experiments correlating the ${ }^{15} \mathrm{~N}$ CSAs with $\mathrm{N}-\mathrm{H}$ dipolar couplings of magnetically aligned $\mathrm{S} 4$ peptide revealed a tilt angle of $40^{\circ}$ and one of two possible rotation angles differing by $180^{\circ}$ [Fig. 3(d)]. Remarkably, this orientation is nearly identical to that in the intact VSD, ${ }^{121}$ suggesting that interactions between S4 and the other helices of the VSD may not be essential for the membrane topology of the gating domain. ${ }^{13} \mathrm{C}-{ }^{31} \mathrm{P}$ distances from the peptide backbone to lipid ${ }^{31} \mathrm{P}$ suggested that DMPC/DMPG bilayers are thinned by $\sim 9 \AA$ at the peptide binding site, which translates to 2 - $\AA$ average thinning of the entire membrane when the peptide/lipid ratio was taken into account. ${ }^{42}$ This result is consistent with neutron diffraction of the KvAP VSD. ${ }^{122}$ REDOR experiments further indicate that the second Arg has a short $\mathrm{C} \zeta$ distance of $4.6 \AA$ to the lipid ${ }^{31} \mathrm{P}$, thus the same guanidinium-phosphate interaction seen in AMPs and CPPs also exist in the S4 helix. This topology and lipid-peptide interaction suggest that the S4 amino acid sequence plays a more important role than previously thought for determining the membrane topol- ogy of the gating segment, possibly without requiring interhelical protein-protein interactions. The tilted orientation of the $\mathrm{S} 4$ helix is reminiscent of the orientation of PG-1 in DLPC bilayers, ${ }^{72}$ despite their different secondary structures, and suggests that the need for Arg molecules to snorkel to the membrane surface may in general disfavor a more upright orientation in the membrane.

\section{Concluding Remarks}

The above survey shows that while cationic membrane peptides and protein domains encompass a large number of functionally diverse molecules with different mechanisms of action, there do exist common atomic and molecular structural features. One common structural feature is that Arg residues form electrostatically and H-bonded complexes with lipid phosphates. Existence of such guanidinium-phosphate salt bridges has been experimentally identified by both distance and dynamic NMR results. These complexes likely have the stoichiometry of two phosphates per guanidinium ion, although it has not been directly proved. Mutation of the Arg molecules significantly altered the function of one AMP and is known to be debilitating for voltage-gated potassium channels. Another general interaction, Arg-water H-bonding, has also be experimentally verified, for example for TAT and PG-1, based on $2 \mathrm{D}{ }^{1} \mathrm{H}-{ }^{13} \mathrm{C}$ and ${ }^{1} \mathrm{H}-{ }^{15} \mathrm{~N}$ correlation NMR. ${ }^{6,52}$ These two interactions can effectively make the free energy of insertion of these cationic peptides favorable (negative).

Our solid-state NMR studies also suggest that the strongest membrane perturbation is caused by peptides with intermediate cationic charge densities and with an amphipathic structure (Table I). At higher Arg densities, peptides such as CPPs become less structured and more dynamic and cause little orientational disorder to the membrane. At lower Arg densities, peptides such as KvAP S4 [Fig. 3(d)] and HNP-1 [Fig. 3(c)] also become less perturbing to the membrane and instead exhibit local interactions between the charged residues and lipid headgroups. How exactly Arg molecules and Lys molecules dictate the topology of this third class of peptides is subtler and future investigations may give more insights into the structural principles behind these systems. Overall, the cationic residues play a significant and possibly central role in dictating the membrane-bound topology of the peptides. Together with the oligomeric structure and dynamics, they underlie the mechanism of action of this large class of membrane peptides and protein domains.

\section{References}

1. Zasloff M (2002) Antimicrobial peptides of multicellular organisms. Nature 415:389-395.

2. Fischer R, Fotin-Mleczek M, Hufnagel H, Brock R (2005) Break on through to the other side-biophysics 
and cell biology shed light on cell-penetrating peptides. ChemBioChem 6:2126-2142.

3. Jiang Y, Lee A, Chen J, Ruta V, Cadene M, Chait BT, MacKinnon R (2003) X-ray structure of a voltage-dependent K+ channel. Nature 423:33-41.

4. Hessa T, Kim H, Bihlmaier K, Lundin C, Boekel J, Andersson H, Nilsson I, White SH, von Heijne G (2005) Recognition of transmembrane helices by the endoplasmic reticulum translocon. Nature 433: 377-381.

5. Popot JL, Engelman DM (1990) Membrane protein folding and oligomerization: the two-stage model. Biochemistry 29:4031-4037.

6. Su Y, Waring AJ, Ruchala P, Hong M (2010) Membrane-bound dynamic structure of an arginine-rich cell-penetrating peptide, the protein transduction domain of HIV TAT, from solid-state NMR. Biochemistry 49:6009-6020.

7. Freites JA, Tobias DJ, von Heijne G, White SH (2005) Interface connections of a transmembrane voltage sensor. Proc Natl Acad Sci USA 102:15059-15064.

8. Herce HD, Garcia AE (2007) Molecular dynamics simulations suggest a mechanism for translocation of the HIV-1 TAT peptide across lipid membranes. Proc Natl Acad Sci USA 104:20805-20810.

9. MacCallum JL, Bennett WF, Tieleman DP (2008) Distribution of amino acids in a lipid bilayer from computer simulations. Biophys J 94:3393-3404.

10. Dorairaj S, Allen TW (2007) On the thermodynamic stability of a charged arginine side chain in a transmembrane helix. Proc Natl Acad Sci USA 104: 4943-4948.

11. Hong M (2006) Solid-state NMR studies of the structure, dynamics, and assembly of beta-sheet membrane peptides and alpha-helical membrane proteins with antibiotic activities. Acc Chem Res 39:176-183.

12. Hong M (2007) Structure, topology, and dynamics of membrane peptides and proteins from solid-state NMR spectroscopy. J Phys Chem B 111:10340-10351.

13. Hong M (2006) Oligomeric structure, dynamics, and orientation of membrane proteins from solid-state NMR. Structure 14:1731-1740.

14. Shen Y, Bryan PN, He Y, Orban J, Baker D, Bax A (2010) De novo structure generation using chemical shifts for proteins with high-sequence identity but different folds. Protein Sci 19:349-356.

15. Hong M (1999) Resonance assignment of $13 \mathrm{C} / 15 \mathrm{~N}$ labeled proteins by two- and three-dimensional magicangle-spinning NMR. J Biomol NMR 15:1-14.

16. Rienstra CM, Hohwy M, Hong M, Griffin RG (2000) 2D and 3D 15N-13C-13C NMR chemical shift correlation spectroscopy of solids: assignment of MAS spectra of peptides. J Am Chem Soc 122:10979-10990.

17. Costa PR, Gross JD, Hong M, Griffin RG (1997) Solidstate NMR measurement of psi in peptides: a NCCN 2Q-heteronuclear local field experiment. Chem Phys Lett 280:95-103.

18. Hong M, Gross JD, Griffin RG (1997) Site-resolved determination of peptide torsion angle phi from the relative orientations of backbone $\mathrm{N}-\mathrm{H}$ and $\mathrm{C}-\mathrm{H}$ bonds by solid-state NMR. J Phys Chem B 101:5869-5874.

19. Sinha N, Hong M (2003) X-1H rotational-echo doubleresonance NMR for torsion angle determination of peptides. Chem Phys Lett 380:742-748.

20. Takegoshi K, Nakamura S, Terao T (2001) 13C-1H dipolar-assisted rotational resonance in magic-angle spinning NMR. Chem Phys Lett 344:631-637.

21. Lewandowski JR, De Paëpe G, Eddy MT, Struppe J, Maas W, Griffin RG (2009) Proton assisted recoupling at high spinning frequencies. J Phys Chem B 113: 9062-9069.

22. Zhang Y, Doherty T, Li J, Lu W, Barinka C, Lubkowski J, Hong M (2010) Resonance assignment and three-dimensional structure determination of a human a-defensin, HNP-1, by solid-state NMR. J Mol Biol 397:408-422.

23. Zhang Y, Lu W, Hong M (2010) The membrane-bound structure and topology of a human $\alpha$-defensin indicate a dimer pore mechanism for membrane disruption. Biochemistry 49:9770-9782.

24. Buffy JJ, Waring AJ, Hong M (2005) Determination of peptide oligomerization in lipid bilayers using $19 \mathrm{~F}$ spin diffusion NMR. J Am Chem Soc 127:4477-4483.

25. deAzevedo ER, Bonagamba TJ, Hu W, Schmidt-Rohr K (1999) Centerband-only detection of exchange: efficient analysis of dynamics in solids by NMR. J Am Chem Soc 121:8411-8412.

26. Luo W, Hong M (2006) Determination of the oligomeric number and intermolecular distances of membrane protein assemblies by anisotropic $1 \mathrm{H}$-driven spin diffusion NMR spectroscopy. J Am Chem Soc 128:7242-7251

27. Schmidt-Rohr K, Hong M (2003) Measurements of carbon to amide-proton distances by $\mathrm{C}-\mathrm{H}$ dipolar recoupling with $15 \mathrm{~N}$ NMR detection. J Am Chem Soc 125:5648-5649.

28. Wi S, Sinha N, Hong M (2004) Long range $1 \mathrm{H}-19 \mathrm{~F}$ distance measurement in peptides by Solid-State NMR. J Am Chem Soc 126:12754-12755.

29. Yamaguchi S, Huster D, Waring A, Lehrer RI, Tack BF, Kearney W, Hong M (2001) Orientation and dynamics of an antimicrobial peptide in the lipid bilayer by solid-state NMR. Biophys J 81:2203-2214.

30. Tang M, Waring AJ, Lehrer RI, Hong M (2008) Effects of guanidinium-phosphate hydrogen bonding on the membrane-bound structure and activity of an arginine-rich membrane peptide from solid-state NMR spectroscopy. Angew Chem Int Ed Engl 47:3202-3205.

31. Cady SD, Goodman C, C. Tatko, DeGrado WF, Hong M (2007) Determining the orientation of uniaxially rotating membrane proteins using unoriented samples: a $2 \mathrm{H}, 13 \mathrm{C}$, and $15 \mathrm{~N}$ solid-state NMR investigation of the dynamics and orientation of a transmembrane helical bundle. J Am Chem Soc 129:5719-5729.

32. Saffman PG, Delbruck M (1975) Brownian motion in biological membranes. Proc Natl Acad Sci USA 72: 3111-3113.

33. Park SH, Das BB, De Angelis AA, Scrima M, Opella SJ (2010) Mechanically, magnetically, and "rotationally aligned" membrane proteins in phospholipid bilayers give equivalent angular constraints for NMR structure determination. J Phys Chem B 114: 13995-14003.

34. Lewis BA, Harbison GS, Herzfeld J, Griffin RG (1985) NMR structural analysis of a membrane protein: bacteriorhodopsin peptide backbone orientation and motion. Biochemistry 24:4671-4679.

35. Doherty T, Waring AJ, Hong M (2008) Dynamic structure of disulfide-removed linear analogs of tachyplesin-I in the lipid bilayer from solid-state NMR. Biochemistry 47:1105-1116.

36. Hester RK, Ackermann JL, Neff BL, Waugh JS (1976) Separated-local-field spectra in NMR. Phys Rev Lett 36:1081-1083.

37. Hong M, Doherty T (2006) Orientation determination of membrane-disruptive proteins using powder samples and rotational diffusion: a simple solid-state NMR approach. Chem Phys Lett 432:296-300. 
38. Tang M, Hong M (2009) Structure and mechanism of beta-hairpin antimicrobial peptides in lipid bilayers from solid-state NMR spectroscopy. Mol Biosyst 5:317-322.

39. Opella SJ, Marassi FM (2004) Structure determination of membrane proteins by NMR spectroscopy. Chem Rev 104:3587-3606.

40. Marassi FM, Opella SJ (2000) A solid-state NMR index of helical membrane protein structure and topology. J Magn Reson 144:150-155.

41. Wang J, Denny J, Tian C, Kim S, Mo Y, Kovacs F, Song Z, Nishimura K, Gan Z, Fu R, Quine JR, Cross TA (2000) Imaging membrane protein helical wheels. J Magn Reson 144:162-167.

42. Doherty T, Su Y, Hong M (2010) High-resolution orientation and depth of insertion of the voltage-sensing $\mathrm{S} 4$ helix of a potassium channel in lipid bilayers. J Mol Biol 401:642-652.

43. Su Y, DeGrado WF, Hong M (2010) Orientation, dynamics, and lipid interaction of an antimicrobial arylamide investigated by $19 \mathrm{~F}$ and $31 \mathrm{P}$ solid-state NMR spectroscopy. J Am Chem Soc 132:9197-9205.

44. Kumashiro KK, Schmidt-Rohr K, Murphy OJ, Ouellette KL, Cramer WA, Thompson LK (1998) A novel tool for probing membrane protein structure: solidstate NMR with proton spin diffusion and X-nucleus detection. J Am Chem Soc 120:5043-5051.

45. Huster D, Yao XL, Hong M (2002) Membrane protein topology probed by $1 \mathrm{H}$ spin diffusion from lipids using solid-state NMR spectroscopy. J Am Chem Soc 124: 874-883.

46. Solomon I (1955) Relaxation processes in a system of two spins. Phys Rev 99:559-565.

47. Buffy JJ, Hong T, Yamaguchi S, Waring A, Lehrer RI, Hong M (2003) Solid-State NMR investigation of the depth of insertion of protegin-1 in lipid bilayers using paramagnetic Mn2+. Biophys J 85:2363-2373.

48. Mani R, Waring AJ, Hong M (2007) Conformation, dynamics, and insertion of a noncysteine-containing protegrin-1 analogue in lipid membranes from solid-state NMR spectroscopy. ChemBioChem 8:1877-1884.

49. Su Y, Mani R, Hong M (2008) Asymmetric insertion of membrane proteins in lipid bilayers by solid-state NMR paramagnetic relaxation enhancement: a cellpenetrating peptide example. J Am Chem Soc 130: 8856-8864.

50. Seelig J (1978) 31P nuclear magnetic resonance and the headgroup structure of phospholipids in membranes. Biochim Biophys Acta 515:105-140.

51. Tang M, Waring AJ, Hong M (2007) Phosphate-mediated arginine insertion into lipid membranes and pore formation by a cationic membrane peptide from solidstate NMR. J Am Chem Soc 129:11438-11446.

52. Li S, Su Y, Luo W, Hong M (2010) Water-protein interactions of an arginine-rich membrane peptide in lipid bilayers investigated by solid-state nuclear magnetic resonance spectroscopy. J Phys Chem B 114: 4063-4069.

53. Brogden KA (2005) Antimicrobial peptides: pore formers or metabolic inhibitors in bacteria? Nat Rev Microbiol 3:238-250.

54. Ganz T (2003) Defensins: antimicrobial peptides of innate immunity. Nat Rev Immunol 3:710-720.

55. Wade D, Boman A, Wahlin B, Drain CM, Andreu D, Boman HG, Merrifield RB (1990) All D-amino acid containing channel forming antibiotic peptides. Proc Natl Acad Sci USA 87:4761-4765.

56. Demchick P, Koch AL (1996) The permeability of the wall fabric of Escherichia coli and Bacillus subtilis. J Bacteriol 178:768-773.
57. Kagan BL, Selsted ME, Ganz T, Lehrer RI (1990) Antimicrobial defensin peptides form voltage-dependent ion-permeable channels in planar lipid bilayer membranes. Proc Natl Acad Sci USA 87:210-214.

58. Lehrer RI, Barton A, Ganz T (1988) Concurrent assessment of inner and outer membrane permeabilization and bacteriolysis in $E$. coli by multiple-wavelength spectrophotometry. J Immunol Methods 108: $153-158$.

59. Schneider T, Kruse T, Wimmer R, Wiedemann I, Sass V, Pag U, Jansen A, Nielsen AK, Mygind PH, Raventós DS, Neve S, Ravn B, Bonvin AM, De Maria L, Andersen AS, Gammelgaard L, Sahl HG, Kristensen $\mathrm{HH}$ (2010) Plectasin, a fungal defensin, targets the bacterial cell wall precursor Lipid II. Science 328: 1168-1172.

60. de Leeuw E, Li C, Zeng P, Li C, Diepeveen-de Buin M, Lu WY, Breukink E, Lu W (2010) Functional interaction of human neutrophil peptide-1 with the cell wall precursor lipid II. FEBS Lett 584:1543-1548.

61. Srinivas N, Jetter P, Ueberbacher BJ, Werneburg M, Zerbe K, Steinmann J, Van der Meijden B, Bernardini F, Lederer A, Dias RL, Misson PE, Henze H, Zumbrunn J, Gombert FO, Obrecht D, Hunziker P, Schauer S, Ziegler U, Käch A, Eberl L, Riedel K, DeMarco SJ, Robinson JA (2010) Peptidomimetic antibiotics target outer-membrane biogenesis in Pseudomonas aeruginosa. Science 327:1010-1013.

62. Epand RM, Vogel HJ (1999) Diversity of antimicrobial peptides and their mechanisms of action. Biochim Biophys Acta 1462:11-28.

63. Baumann G, Mueller P (1974) A molecular model of membrane excitability. J Supramol Struct 2:538-557.

64. He K, Ludtke SJ, Worcester DL, Huang HW (1996) Neutron scattering in the plane of membranes: structure of alamethicin pores. Biophys J 70:2659-2666.

65. Huang HW, Chen FY, Lee MT (2004) Molecular mechanism of peptide-induced pores in membranes. Phys Rev Lett 92:198304.

66. Matsuzaki K (1999) Why and how are peptide-lipid interactions utilized for self-defense? Magainins and tachyplesins as archetypes. Biochim Biophys Acta 1462:1-10.

67. Bechinger B (1999) The structure, dynamics, and orientation of antimicrobial peptides in membranes by multidimensional solid-state NMR spectroscopy. Biochim Biophys Acta 1462:157-183.

68. Kokryakov VN, Harwig SS, Panyutich EA, Shevchenko AA, Aleshina GM, Shamova OV, Korneva HA, Lehrer RI (1993) Protegrins: leukocyte antimicrobial peptides that combine features of corticostatic defensins and tachyplesins. FEBS Lett 327:231-236.

69. Bellm L, Lehrer RI, Ganz T (2000) Protegrins: new antibiotics of mammalian origin. Expert Opin Investig Drugs 9:1731-1742.

70. Chen J, Falla TJ, Liu H, Hurst MA, Fujii CA, Mosca DA, Embree JR, Loury DJ, Radel PA, Cheng CC, Gu L, Fiddes JC (2000) Development of protegrins for the treatment and prevention of oral mucositis: structureactivity relationships of synthetic protegrin analogues. Biopolymers 55:88-98.

71. Buffy JJ, Waring AJ, Lehrer RI, Hong M (2003) Immobilization and aggregation of the antimicrobial peptide protegrin-1 in lipid bilayers investigated by solid-state NMR. Biochemistry 42:13725-13734.

72. Yamaguchi S, Hong T, Waring A, Lehrer RI, Hong M (2002) Solid-state NMR investigations of peptide-lipid interaction and orientation of a beta-sheet antimicrobial peptide, protegrin. Biochemistry 41:9852-9862. 
73. Fahrner RL, Dieckmann T, Harwig SS, Lehrer RI, Eisenberg D, Feigon J (1996) Solution structure of protegrin-1, a broad-spectrum antimicrobial peptide from porcine leukocytes. Chem Biol 3:543-550.

74. Mani R, Buffy JJ, Waring AJ, Lehrer RI, Hong M (2004) Solid-state NMR investigation of the selective disruption of lipid membranes by protegrin-1. Biochemistry 43:13839-13848.

75. Marasinghe PAB, Buffy JJ, Schmidt-Rohr K, Hong M (2005) Membrane curvature change induced by an antimicrobial peptide detected by 31P exchange NMR. J Phys Chem B 109:22036-22044.

76. Mani R, Tang M, Wu X, Buffy JJ, Waring AJ, Sherman MA, Hong M (2006) Membrane-bound dimer structure of a b-hairpin antimicrobial peptide from rotational-echo double-resonance solid-state NMR. Biochemistry 45:8341-8349.

77. Mani R, Cady SD, Tang M, Waring AJ, Lehrer RI, Hong M (2006) Membrane-dependent oligomeric structure and pore formation of a beta-hairpin antimicrobial peptide in lipid bilayers from solid-state NMR. Proc Natl Acad Sci USA 103:16242-16247.

78. Yang L, Weiss TM, Lehrer RI, Huang HW (2000) Crystallization of antimicrobial pores in membranes: magainin and protegrin. Biophys J 79:2002-2009.

79. Mani R, Waring AJ, Lehrer RI, Hong M (2005) Membrane-disruptive abilities of beta-hairpin antimicrobial peptides correlate with conformation and activity: a 31P and 1H NMR study. Biochim Biophys Acta 1716: 11-18.

80. Tang M, Waring AJ, Hong M (2009) Effects of arginine density on the membrane-bound structure of a cationic antimicrobial peptide from solid-state NMR. Biochim Biophys Acta 1788:514-521.

81. Su Y, Waring AJ, Ruchala P, Hong M, Structures of $\beta$ hairpin antimicrobial protegrin peptides in lipopolysaccharide membranes: mechanism of gram selectivity obtained from solid-state NMR. Biochemistry, Epub ahead of print, DOI: 10.1021/bi101975v.

82. Nakamura T, Furunaka H, T TM, Tokunaga F, Muta T, Iwanaga S, Niwa M, Takao T, Shimonishi Y (1988) Tachyplesin, a class of antimicrobial peptide from the hemocytes of the horseshoe crab (Tachypleus tridentatus). Isolation and chemical structure. J Biol Chem 263:16709-16713.

83. Doherty T, Waring AJ, Hong M (2006) Peptide-lipid interactions of the beta-hairpin antimicrobial peptide tachyplesin and its linear derivatives from solid-state NMR. Biochim Biophys Acta 1758:1285-1291.

84. Laederach A, Andreotti AH, Fulton DB (2002) Solution and micelle-bound structures of tachyplesin I and its active aromatic linear derivatives. Biochemistry 41:12359-12368.

85. Doherty T, Waring AJ, Hong M (2006) Membranebound conformation and topology of the antimicrobial peptide tachyplesin-I by solid-state NMR Biochemistry 45:13323-13330.

86. Hill CP, Yee J, Selsted ME, Eisenberg D (1991) Crystal structure of defensin HNP-3, an amphiphilic dimer: mechanisms of membrane permeabilization. Science 251:1481-1485.

87. Szyk A, Wu Z, Tucker K, Yang D, Lu W, Lubkowski J (2006) Crystal structures of human alpha-defensins HNP4, HD5, and HD6. Protein Sci 15:2749-2760.

88. Wimley WC, Selsted ME, White SH (1994) Interactions between human defensins and lipid bilayers: evidence for formation of multimeric pores. Protein Sci 3: 1362-1373.
89. Pazgier M, Lubkowski J (2006) Expression and purification of recombinant human alpha-defensins in Escherichia coli. Protein Expr Purif 49:1-8.

90. Baldus M (2006) Solid-state NMR spectroscopy: molecular structure and organization at the atomic level. Angew Chem Int Ed Engl 45:1186-1188.

91. McDermott AE (2009) Structure and dynamics of membrane proteins by magic angle spinning solidstate NMR. Annu Rev Biophys 38:385-403.

92. Li S, Zhang Y, Hong M (2010) 3D 13C-13C-13C correlation NMR for de novo distance determination of solid proteins and application to a human alpha defensin. J Magn Reson 202:203-210.

93. Fawell S, Seery J, Daikh Y, Moore C, Chen LL, Pepinsky B, Barsoum J (1994) Tat-mediated delivery of heterologous proteins into cells. Proc Natl Acad Sci USA 91:664-668.

94. Gratton JP, Yu J, Griffith JW, Babbitt RW, Scotland RS, Hickey R, Giordano FJ, Sessa WC (2003) Cell-permeable peptides improve cellular uptake and therapeutic gene delivery of replication-deficient viruses in cells and in vivo. Nat Med 9:357-362.

95. Torchilin VP, Levchenko TS, Rammohan R, Volodina N, Papahadjopoulos-Sternberg B, D'souza GG (2003) Cell transfection in vitro and in vivo with nontoxic TAT peptide-liposome-DNA complexes. Proc Natl Acad Sci USA 100:1972-1977.

96. Frankel AD, Pabo CO (1988) Cellular uptake of the tat protein from human lmmunodeficiency virus. Cell 55:1189-1193.

97. Green ML, Loewenstein PM. (1988) Autonomous functional domains of chemically synthesized human immunodeficiency virus tat trans-activator protein. Cell 55:1179-1188.

98. Derossi D, Joliot AH, Chassaing G, Prochiantz A (1994) The third helix of the Antennapedia homeodomain translocates through biological membranes. J Biol Chem 269:10444-10450.

99. Khafagya E-S, Morishitaa M, Isowab K, Imaib J, Takayamaa K (2009) Effect of cell-penetrating peptides on the nasal absorption of insulin. J Contol Release 133:103-108.

100. Rothbard JB, Jessop TC, Lewis RS, Murray BA, Wender PA (2004) Role of membrane potential and hydrogen bonding in the mechanism of translocation of guanidinium-rich peptides into cells. J Am Chem Soc 126:9506-9507.

101. Futaki S, Suzuki T, Ohashi W, Yagami T, Tanaka S, Ueda K, Sugiura Y (2001) Arginine-rich peptides. An abundant source of membrane-permeable peptides having potential as carriers for intracellular protein delivery. J Biol Chem 276:5836-5840.

102. White SH, Wimley WC (1999) Membrane protein folding and stability: physical principles. Annu Rev Biophys Biomol Struct 28:319-365.

103. Czajlik A, Meskó E, Penke B, Perczel A (2002) Investigation of penetratin peptides. Part 1 . The environment dependent conformational properties of penetratin and two of its derivatives. J Pept Sci 8: 151-171.

104. Berlose JP, Convert O, Derossi D, Brunissen A, Chassaing G (1996) Conformational and associative behaviours of the third helix of antennapedia homeodomain in membrane-mimetic environments. Eur J Biochem 242:372-386.

105. Clayton AH, Atcliffe BW, Howlett GJ, Sawyer WH (2006) Conformation and orientation of penetratin in phospholipid membranes. J Pept Sci 12:233-238. 
106. Lindberg M, Biverstahl H, Graslund A, Maler L (2003) Structure and positioning comparison of two variants of penetratin in two different membrane mimicking systems by NMR. Eur J Biochem 270: 3055-3063.

107. Su Y, Mani R, Doherty T, Waring AJ, Hong M (2008) Reversible sheet-turn conformational change of a cellpenetrating peptide in lipid bilayers studied by solidstate NMR. J Mol Biol 381:1133-1144.

108. Su Y, Doherty T, Waring AJ, Ruchala P, Hong M (2009) Roles of arginine and lysine residues in the translocation of a cell-penetrating peptide from 13C, 31P, and $19 F$ solid-state NMR. Biochemistry 48:4587-4595.

109. Binder H, Lindblom G (2003) Charge-dependent translocation of the Trojan peptide penetratin across lipid membranes. Biophys J 85:982-995.

110. Mitchell DJ, Kim DT, Steinman L, Fathman CG, Rothbard JB (2000) Polyarginine enters cells more efficiently than other polycationic homopolymers. J Pept Res 56:318-325.

111. Amand HL, Fant K, Nordén B, Esbjörner EK (2008) Stimulated endocytosis in penetratin uptake: effect of arginine and lysine. Biochem Biophys Res Commun 371:621-625.

112. Wimley WC, White SH (1996) Experimentally determined hydrophobicity scale for proteins at membrane interfaces. Nat Struct Biol 3:842-848.

113. Torchilin VP, Rammohan R, Weissig V, Levchenko TS (2001) TAT peptide on the surface of liposomes affords their efficient intracellular delivery even at low temperature and in the presence of metabolic inhibitors. Proc Natl Acad Sci USA 98:8786-8791.

114. Ziegler A, LiBlatter X, Seelig A, Seelig J (2003) Protein transduction domains of HIV-1 and SIV TAT interact with charged lipid vesicles. Binding mechanism and thermodynamic analysis. Biochemistry 42: 9185-9194.

115. Richard JP, Melikov K, Vives E, Ramos C, Verbeure B, Gait MJ, Chernomordik LV, Lebleu B (2003) Cellpenetrating peptides. A reevaluation of the mechanism of cellular uptake. J Biol Chem 278:585-590.

116. Derossi D, Calvet S, Trembleau A, Brunissen A, Chassaing G, Prochiantz A (1996) Cell internalization of the third helix of the Antennapedia homeodomain is receptor-independent. J Biol Chem 271: 18188-18193.

117. Herce HD, Garcia AE, Litt J, Kane RS, Martin P, Enrique N, Rebolledo A, Milesi V (2009) Arginine-rich peptides destabilize the plasma membrane, consistent with a pore formation translocation mechanism of cell-penetrating peptides. Biophys J 97:1917-1925.

118. Seoh SA, Sigg D, Papazian DM, Bezanilla F (1996) Voltage-sensing residues in the S2 and S4 segments of the Shaker K+ channel. Neuron 16:1159-1167.

119. Swartz KJ (2008) Sensing voltage across lipid membranes. Nature 456:891-897.

120. Cuello LG, Cortes DM, Perozo E (2004) Molecular architecture of the KvAP voltage-dependent $\mathrm{K}+$ channel in a lipid bilayer. Science 306:491-495.

121. Long SB, Tao X, Campbell EB, MacKinnon R (2007) Atomic structure of a voltage-dependent $\mathrm{K}+$ channel in a lipid membrane-like environment. Nature 450: 376-383.

122. Krepkiy D, Mihailescu M, Freites JA, Schow EV, Worcester DL, Gawrisch K, Tobias DJ, White SH, Swartz KJ (2009) Structure and hydration of membranes embedded with voltage-sensing domains. Nature 462:473-479. 